\title{
ESTIMATION OF RELATIVE RISK OF DEVELOPMENT AND INFORMATIVENESS OF DIAGNOSTIC METHODS OF HYPERPROLIFERATIVE PROCESSES OF ENDOMETRIUM
}

DOI: 10.36740/WLek202009220

\author{
Alla V. Boychuk', Tetiana V. Vereshchahina' ${ }^{1}$ Iryna M. Nikitina' ${ }^{2}$ \\ 'TERNOPIL STATE MEDICAL UNIVERSITY NAMED AFTER I. YA. GORBACHEVSKY, TERNOPIL, UKRAINE \\ ${ }^{2}$ SUMY STATE UNIVERSITY, SUMY, UKRAINE
}

\begin{abstract}
The aim: To conduct a comparative analysis of the results of ultrasound and hysteroscopic examinations with further histopathological findings and the clinical and anamnestic features of patients with hyperproliferative pathology in order to determine the etiopathogenetic mechanisms of the development of endometrial pathological processes. Materials and methods: We studied 119 medical records of patients of the Gynecological Department of Minipal Non-Commercial Enterprise "Ternopil Municipal City Hospital NN. 2", who applied for medical assistance because of benign endometrial hyperplasia in the reproductive age with a verified diagnosis of "uterine polyp" during $2017-2018$. The control group consisted of 30 patients of the same age group, with menstrual disorders with no signs of hyperplastic processes of endometrium. With the consent of the patients, they were treated with diagnostic hysteroscopy in order to study evacuated material from the uterus. The results of the histological study confirmed the absence of signs of hyperplastic processes of endometrium. The results of diagnostic methods were evaluated by comparing the material's histological data with the results of ultrasound and hysteroresectoscopy.

Results: Taking into account the results of our research, women with hyperplastic processes of endometrium have the risk of the pathology of the nervous system is in 2.71 times

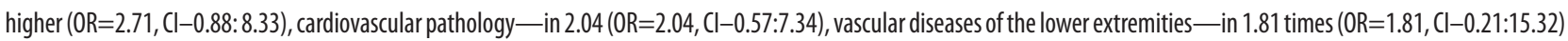
compared with the control group. While the risk of pathology of the urinary system and organs of vision is only $-0 \mathrm{R}=0.48, \mathrm{Cl}-0.11: 2.03$ and $0 \mathrm{R}=0.75, \mathrm{Cl}-0.08: 7.48$, respectively. Analyzing the results of the study using ultrasound examination, it was found that endometrial polyposis in combination with uterine leiomyoma was not detected in 3 women (15\%), while all the results of hysteroscopy were confirmed by histopathological studies. When the endometrial hyperplastic processes were combined with adenomyosisaccording to ultrasound examination a false positive result was obtained in 2 patients (13.3\%), and in a hysteroscopic study we determined - 1 false positive result. In patients the diagnosis of "endometrial polyp" according to the results of hysteroscopy was not confirmed in 2 women ( 2 false positive results $2.99 \%$ ) and in 5 cases of ultrasound examination ( 5 false negative results $7.46 \%$ ). The use of ultrasound examinations in patients with endometrial hyperplastic changes, according to our data, made it possible to identify pathology in $88.39 \%$ of cases, while the information content of the hysteroscopy was $98.21 \%(p<0.001)$.

Conclusions: Thus, the results of the subjective examination of patients in the gynecological department: complaints, anamnestic data on gynecological and extragenital pathology should be used to identify etiopathogenetic factors and the formation of risk groups for the occurrence of hyperplastic processes of endometrium. Women with cervical erosion, uterine myoma and episodes of herpetic rash on the mucous membranes in past medical history have a higher likelihood of hyperplastic processes of endometrium. The vast majority of patients (63.87\%) with polyps of the body of the uterus have a combined hyperproliferative pathology, which requires an individual approach to planning the scope of diagnostic examination and the choice of treatment method. Visualization of endometrium with hysteroscopy is more informative than ultrasound for diagnosing hyperproliferative processes, including uterine polyps. Hysteroscopic polypectomy has a high level of both clinical and economic benefits as well as diagnostic value in patients with hyperplastic processes of endometrium.
\end{abstract}

KEY WORDS: hyperproliferative pathology, hyperplastic processes of endometrium, hysteroscopic examinations

Wiad Lek. 2020;73(9 p. II):2004-2009

\section{INTRODUCTION}

The problem of hyperplastic processes of endometrium (HPE) occupies one of the main places in gynecological practice and constitutes (according to various sources) from $17 \%$ to $59 \%$ of the total gynecological pathology [10, 11]. The interest in improving the diagnosis and treatment of benign hyperproliferative lesions of the uterus is not only necessary and expedient from the standpoint of oncological alertness, but also given the frequent recurrences of patho- logical changes, reproductive disorders in this category of women, disorders of the ovarian-menstrual cycle and the development of chronic anemia.

Diagnostics of the endometrial polyps (EP) does not cause any particular difficulties and has a clear algorithm of actions: visualization of formation, its evacuation followed by histopathological studies (HS) to optimize the further tactics of the patient management [2]. At the same time, the curettage of the uterus and a "blind" biopsy are 
not the methods of choice today for diagnosing polyps of the uterus. When using this method, there is a risk of fragmentation of the polyp tissue, which often complicates the work of the histologist [3].

Today, the direct endoscopic visualization of the endometrial cavity (hysteroscopy) is considered the "gold standard" in the diagnosis and treatment of polyps of the uterus body, and hysteroscopic polypectomy [4-6], which is deservedly called as "See-and-Treat" method [7]. Nowadays, the method of hysteroscopy is widely used in many countries of the world, it is included in the standards of examination and treatment of patients with various gynecological pathologies. Analysis of the diagnostic value (sensitivity and specificity) of this method of examination and treatment of patients with various pathologies of the female reproductive system confirmed not only the diagnostic sensitivity, but also the economic feasibility of using hysteroscopy $[1,9]$.

In particular, the meta-analytical study that analyzed the hysteroscopic data of the main pathological changes in the endometrium in women with blood secretions from the genital tracts (based on Medline and the Cochrane Library data) revealed a high diagnostic accuracy of hysteroscopy for endometrial cancer, endometrial polyp and submucous leiomyoma [8].

Considering the above, to study the diversity of the clinical presentation of hyperproliferative pathology, we have analyzed and summarized the clinical and anamnestic data, parity, considered the accompanying pathology, and also analyzed the results of ultrasound and hysteroscopic examinations with further histopathological findings.

\section{THE AIM}

The aim to conduct a comparative analysis of the results of ultrasound and hysteroscopic examinations with further histopathological findings and the clinical and anamnestic features of patients with hyperproliferative pathology in order to determine the etiopathogenetic mechanisms of the development of endometrial pathological processes.

\section{MATERIALS AND METHODS}

We studied 119 medical records of patients of the Gynecological Department of Minipal Non-Commercial Enterprise “Ternopil Municipal City Hospital No. 2", who applied for medical assistance because of benign endometrial hyperplasia in the reproductive age with a verified diagnosis of "uterine polyp" during 2017-2018. The age of women ranged from 20 to 49 years (on average $34.52 \pm$ 2.51). The research group included patients with simple and complex non-atypical endometrial hyperplasia according to the classification of hyperproliferative processes of endometrium (developed by the Subcommittee on Uterine Corpus of the International Society of Gynecologists and Pathologists and approved by WHO, 1994). According to its data, hyperplastic processes of endometrium are divided into 5 groups:
- simple non-atypical endometrial hyperplasia;

- complex non-atypical endometrial hyperplasia;

- simple atypical endometrial hyperplasia;

- complex atypical endometrial hyperplasia;

- adenocarcinoma

The study group did not include medical records of women with alimentary-constitutional obesity (BMI>30.0).

The control group consisted of 30 patients of the same age group, with menstrual disorders with no signs of HPE. With the consent of the patients, they were treated with diagnostic hysteroscopy in order to study evacuated material from the uterus. The results of the histological study confirmed the absence of signs of HPE.

Ultrasound examination (US) was carried out on the device "Philips HD11 XE" with a $3.5 \mathrm{MHz}$ convex sensor and a $7.5 \mathrm{MHz}$ vaginal sensor. Sonographic studies were conducted in the proliferative (6-8 day) or secretory (20-22 day) phases of the menstrual cycle.

Hysteroscopy was performed in the operative room with intravenous anesthesia on hard fiber optics of Companies "KARL STORZ" from the 6th to the 11th day of the menstrual cycle (with the menstrual cycle preserved). Taking into account the results of ultrasound and hysteroscopy data, a resectoscope was used to completely remove the hyperplastic cells of the uterus and the cervical canal with further follow-up examination. After complete removal of the pathologically altered endometrial tissue, the resulting material was sent for histological examination. The material was fixed in $10 \%$ buffered formalin solution. Histological examination of tissues was performed by the standard method of serial sections (paraffin sections were stained with hematoxylin-eosin and according to Van Gieson). The findings on the histological types of hyperplasia and endometrial polyps were based on the WHO classification for endometrial pathology (2014).

The results of diagnostic methods were evaluated by comparing the material's histological data with the results of ultrasound and hysteroresectoscopy.

All diagnostic and therapeutic manipulations were carried out after the written consent of the patients for examination and treatment in accordance with the protocol approved by the Committee on Bioethics (No. 53/June 03, 2019). Consent for surgical treatment was obtained prior to treatment.

The obtained data was processed using standard statistical methods using HP PREMIER EXPERIENCE personal computer with program Microsoft Word 2010, the graphics were built using Microsoft Excel. Statistical processing was carried out by the program Statistika 10. For statistical processing, the qualitative and quantitative variables were determined. For qualitative data, a frequency analysis of the occurrence of signs was performed with the determination of the error of the mid and $95 \%$ confidence interval. The quantitative variables were checked for normal distribution using descriptive statistics of criteria of Kolmogorov-Smirnov. For risk assessment there were determined the odds ratio, confidence intervals, relative risk, etiological factor of influence, absolute (directly associated risk), percentage of associated risk and population risk. 
Table I. Relative risk of complaints in patients with hyperplastic processes of endometrium

\begin{tabular}{lcccc} 
No. & Complaints & OR & \multicolumn{2}{c}{ Confidence interval } \\
\cline { 3 - 5 } & & 0,8 & lower bound & upper bound \\
\hline 1 & disorder of the menstrual cycle & 2,39 & 0,34 & 8,53 \\
\hline 2 & Pain & 1,31 & 0,67 & 4,18 \\
\hline 3 & frequent and significant menstruation & 0,66 & 0,20 & 2,25 \\
\hline 4 & Infertility & 1,01 & 0,10 & 9,40 \\
\hline 5 & general weakness & 1,5 & 0,41 & 5,50 \\
\hline 7 & without significant complaints & 0,36 & 0,11 & 1,19 \\
\hline
\end{tabular}

Table II. The relative risk of hyperplastic processes of endometrium in patients with concomitant gynecological pathology

\begin{tabular}{|c|c|c|c|c|}
\hline \multirow{2}{*}{ No. } & \multirow{2}{*}{ Gynecological anamnesis } & \multirow{2}{*}{ OR } & \multicolumn{2}{|c|}{ Confidence interval } \\
\hline & & & lower bound & upper bound \\
\hline 1 & erosion of the cervix & 5,71 & 2,17 & 15,02 \\
\hline 2 & ovarian cysts & 2,95 & 0,37 & 23,83 \\
\hline 3 & chronic inflammatory diseases of the uterine appendages & 3,29 & 1,07 & 10,08 \\
\hline 4 & ectopic pregnancy & 0,50 & 0,04 & 5,66 \\
\hline 5 & mammary pathology & 1,43 & 0,30 & 6,81 \\
\hline 6 & polyps of the cervical canal & 1,01 & 0,11 & 9,37 \\
\hline 7 & myoma of the uterus & 6,21 & 0,8 & 48,19 \\
\hline 8 & herpetic rash on mucous membranes & 5,05 & 1,66 & 15,36 \\
\hline 9 & combined pathology & 9,8 & 2,23 & 43,06 \\
\hline
\end{tabular}

\section{RESULTS}

Analysis of the results of the subjective examination showed that the most frequent complaints when admission to hospital in patients with endometrial hyperproliferative processes were menstrual disorders-(27 women-28.57\%), pain (25 patients-21.01\%\%), frequent and significant menstruation (20 patients- $16.81 \%)$, infertility in 11 cases (9.24\%), 4 women felt general weakness (3.36\%), a combination of complaints was found in 17 cases (14.29\%), without special complaints were 8 women $(6.72 \%)(\mathrm{p}=0.01)$. The relative risk $(\mathrm{RR})-\mathrm{OR}$ was calculated-the occurrence of these complaints at admission to hospital of patients with HPE compared with the control group. The above data are shown in table I.

The maximum duration of this disease was 15 years, the minimum-2 weeks.

Fourty-forty patients (36.97\%) received prior treatment for HPE: 10 women $(8.40 \%)$ were prescribed hormone therapy, in 5 cases $(4.20 \%)$ was used anti-inflammatory therapy. Firty percent of patients indicated on fractional therapeutic and diagnostic curettage (FTDC) in the past medical history: 17 women-once (14.29\%), 5-two or more times $(4.2 \%)$. Hormone therapy after FTDC received 7 patients $(22.73 \%)(\mathrm{p}<0.005)$.

Assessment of the relative risk of HPE taking into account the peculiarities of the gynecological past medical history. The above data are shown in table II.
When specifying the gynecological past medical history, cervical erosion was found in 70 women $(62.2 \%), 40$ patients (35.5\%) suffered from chronic inflammatory diseases of the uterine appendages, 21 women (18.4\%) reported uterine myoma, ovarian cysts were diagnosed in 11 patients (9.6\%), 4 women (3.8\%) noted polyps of the cervical canal in their past medical history, 2 women $(1.8 \%)$ had ectopic pregnancies. Breast pathology was documented in 11 medical records $(9.6 \%)$, in addition there were periodic herpetic rash on the mucous membranes-52 (43.70\%) ( $\mathrm{p}<0.005)$. Combined pathology was observed in 49 women $(41.18 \%)$. A detailed study of reproductive function showed that 22 women had 1 birth in their past medical history (18.49\%), 32 gave birth 2 times or more (26.89\%). Women who did not give birth amounted $48.74 \%$ (58 patients). Twenty-six and six hundredths percent of patients had abortions in their anamnesis, among them 1 abortion-16 women (13.45\%), 2 or more-15 (12.61\%), and 81 women had no abortions in their anamnesis $(68.07 \%)$. For the purpose of contraception, 19 patients $(11.9 \%)$ had IUDs, 9 patients used hormonal contraceptives $(7.56 \%)$ ( $p<0.005)$.

An extragenital pathology was detected in 74 patients $(64.18 \%)$, of which $25.21 \%$ was combined $(\mathrm{p}<0.005)$. The structure of associated diseases revealed: changes in the cardiovascular system in $18.49 \%$ of patients, diseases of the nervous system in $29.41 \%$, pathology of the gastroin- 


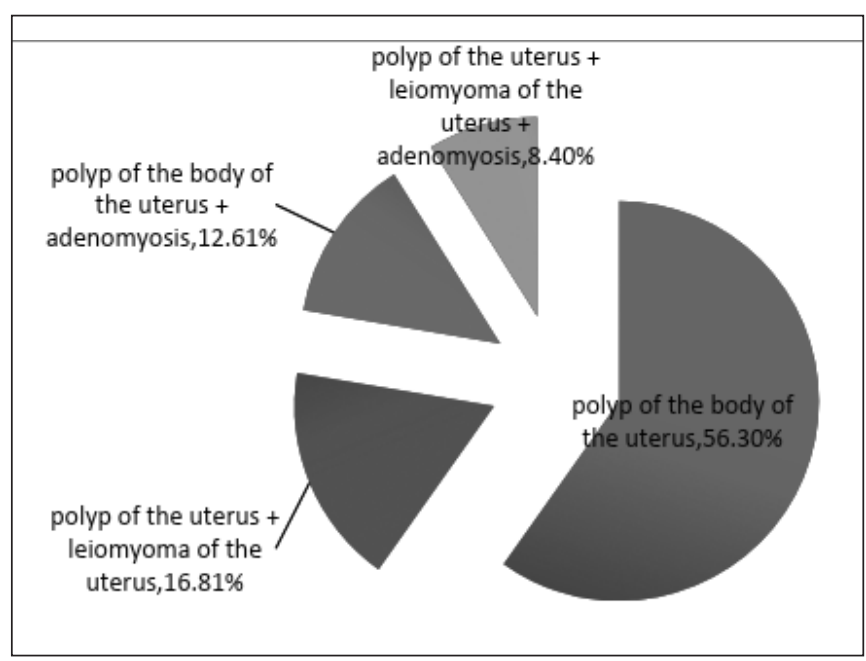

Fig 1. Structure of hyperproliferative pathology of myometrium and endometrium

testinal tract- $15.97 \%$, diseases of the urinary-excretory system $-5.04 \%$, respiratory systems $-8.40 \%$, endocrinopathy- $29.41 \%$, varicose disease of the lower extremities-5.88\%, ophthalmic pathology-2.52\%.

A comparative analysis of the presence of extragenital pathology with the risk assessment in women with HPE in different systems of the body was conducted. The above data are shown in table III.
According to the results of the conducted clinical laboratory research, the most commonly diagnosed isolated pathology of endometrium was a polyp (56.30), while in 31 women $(26.05 \%)$ polyps were detected not only in the uterine cavity, but also in the cervical canal. In 20 cases (16.81\%), the uterine polyp was combined with hyperproliferative uterine disease-leiomyoma. The combination of the uterine polyp with adenomyosis was detected in 15 patients $(12.61 \%)$. A leiomyoma with adenomyosis was diagnosed with the uterine polyp in 10 patients (8.40\%).

During the study of the structure of hyperproliferative pathology in these patients there was revealed a combined pathology of myo- and endometrium. The above data are shown in Figure 1.

A comparative assessment of the informativeness of ultrasound and hysteroscopy with the final results of a histopathological study in the diagnosis of endometrial hyperplasia was carried out. The above data are shown in table IV.

The analysis of the results of subjective examination of patients with HPE showed frequent pain syndrome in comparison with the control group in 2.71 times $(\mathrm{OR}=2.71$, CI-0.88:8.33). At the same time, patients with HPE often had complains on frequent and heavy menstruation, a general weakness in $1.31(\mathrm{OR}=1.31, \mathrm{CI}-0.41: 4.18)$ and 1.01 (OR=1.01, CI-0, 10:9.40) times, respectively. While complaints on infertility and menstrual dysfunction have no significant relative risk values: $\mathrm{OR}=0.66, \mathrm{CI}-0.20: 2.25$ and $\mathrm{OR}=0.8 \mathrm{CI}-0.34: 1.88$, respectively.

Table III. Risk assessment for body systems in women with hyperplastic processes of endometrium compared with the control group.

\begin{tabular}{|c|c|c|c|c|c|}
\hline \multirow{2}{*}{ No. } & \multirow{2}{*}{ Gynecological anamnesis } & \multirow{2}{*}{ Number of women } & \multirow{2}{*}{$\begin{array}{c}\text { OR } \\
\text { lower } \\
\text { bound }\end{array}$} & \multicolumn{2}{|c|}{ Confidence interval } \\
\hline & & & & upper bound & \\
\hline 1 & diseases of cardiovascular system & 22 & 2,04 & 0,57 & 7,34 \\
\hline 2 & diseases of the nervous system & 35 & 2,71 & 0,88 & 8,33 \\
\hline 3 & pathology of the gastrointestinal tract & 19 & 1,24 & 0,39 & 3,94 \\
\hline 4 & diseases of the urinary excretory system & 6 & 0,48 & 0,11 & 2,03 \\
\hline 5 & diseases of respiratory system & 10 & 1,28 & 0,27 & 6,20 \\
\hline 6 & endocrinopathy & 24 & 1,01 & 0,37 & 2,75 \\
\hline 7 & varicose disease of the lower extremities & 7 & 1,81 & 0,21 & 15,32 \\
\hline 8 & ophthalmic pathology & 3 & 0,75 & 0,075 & 7,48 \\
\hline 9 & combined pathology & 30 & 2,19 & 0,71 & 6,79 \\
\hline
\end{tabular}

Table IV. Structure of detected pathology of endometrium by ultrasound, hysteroscopic examination and HS.

\begin{tabular}{|c|c|c|c|}
\hline Diagnosis & Ultrasound & Hysteroscopy & Result of HS \\
\hline Polyposis & $\begin{array}{c}62 \\
5 \text {-false negative }\end{array}$ & $\begin{array}{c}69 \\
\text { 2-false negative }\end{array}$ & 67 \\
\hline Polyposis of endometrium with leiomyoma of the uterus & $\begin{array}{c}16 \\
3 \text {-false negative }\end{array}$ & 20 & 20 \\
\hline Polyposis of endometrium with adenomyosis & $\begin{array}{c}18 \\
2 \text {-false positive }\end{array}$ & $\begin{array}{c}16 \\
1 \text {-false positive }\end{array}$ & 15 \\
\hline $\begin{array}{l}\text { Polyposis of endometrium with leiomyoma of the uterus and } \\
\qquad \text { adenomyosis }\end{array}$ & $\begin{array}{c}13 \\
3 \text {-false positive }\end{array}$ & 10 & 10 \\
\hline
\end{tabular}


Taking into account these complaints, it is noteworthy that women with HPE have an increase in pain in 2.39 $(\mathrm{OR}=2.71, \mathrm{CI}-0.88: 8.33)$ times higher in comparison with healthy patients.

Analysis of the results of the gynecological anamnesis showed that the relative risk of HPE in patients with cervical erosion is 5.71, chronic inflammatory diseases of the uterine appendages-3.29, uterine myoma-6.21, ovarian cysts- 2.95 , polyps of the cervical canal $-1,01$, ectopic pregnancies-0.50, breast pathology-1.43 (Table 2). Thus, women with cervical erosion and uterine myoma have the risk of HPE respectively in 5.71 times $(\mathrm{OR}=5.71$, CI-2.17:15.02) and 6.21 times (OR=6.21, CI-2.17:15.02) higher than in the control group. Interesting was the fact that the increase in the probability of the occurrence of HPE in women with past herpetic rash on the mucous membranes was by 5.05 times (OR=5.05, $\mathrm{CI}-1.66: 15.36)$. Whereas the confidence interval in women, who had ectopic pregnancies in their anamnesis, does not have a significant difference $(\mathrm{OR}=0.5$, DI-0.04:5.66)

Thus, anamnestic data on cervical erosion, uterine myoma and episodes of herpetic rash on the mucous membranes can be assessed as specific and used to form risk groups.

Taking into account the results of our research, women with HPE have the risk of the pathology of the nervous system is in 2.71 times higher $(\mathrm{OR}=2.71$, CI-0.88: 8.33), cardiovascular pathology-in $2.04(\mathrm{OR}=2.04, \mathrm{CI}-0.57: 7.34)$, vascular diseases of the lower extremities-in 1.81 times $(\mathrm{OR}=1.81, \mathrm{CI}-0.21: 15.32)$ compared with the control group. While the risk of pathology of the urinary system and organs of vision is only- $\mathrm{OR}=0.48, \mathrm{CI}-0.11: 2.03$ and $\mathrm{OR}=0.75$, CI-0.08:7.48, respectively.

Thus, the results of the evaluation of premorbid conditions in patients with HPE require timely diagnostic and medical-preventive activities regarding the occurrence of this pathology.

\section{DISCUSSION}

The results of the conducted analysis indicate a significant percentage of patients with combined endometrial pathology, which indicates the need to conduct a more detailed and in-depth study of the state of endo- and myometrium when uterine body polyps are detected using not only sufficiently informative, but also economically grounded diagnostic methods. These results are obviously crucial for the choice of treatment tactics. Frequent concomitant extragenital diseases necessitate an individual approach, both in the choice of adequate diagnostic methods and in effective treatment tactics.

Analyzing the results of the study using ultrasound examination, it was found that endometrial polyposis in combination with uterine leiomyoma was not detected in 3 women (15\%), while all the results of hysteroscopy were confirmed by HS. When the endometrial hyperplastic processes were combined with adenomyosis-according to ultrasound examination a false positive result was ob- tained in 2 patients (13.3\%), and in a hysteroscopic study we determined -1 false positive result.

In patients the diagnosis of "endometrial polyp" according to the results of hysteroscopy was not confirmed in 2 women ( 2 false positive results $2.99 \%$ ) and in 5 cases of ultrasound examination ( 5 false negative results $7.46 \%$ ). The clinical diagnosis in these patients was verified using HS.

The use of ultrasound examinations in patients with endometrial hyperplastic changes, according to our data, made it possible to identify pathology in $88.39 \%$ of cases, while the information content of the hysteroscopy was 98.21\% ( $\mathrm{p}<0.001)$. The results of the study confirm the opinion about the need to use the possibilities of ultrasound and hysteroscopic examinations as complementary methods for the diagnosis of endometrial hyperplastic processes. At the same time, the data obtained by us testify the advantages of visualization of endometrial polyps in a gynecological department of hospital in favor of a hysteroscopic examination.

Considering our findings, it can be said that visualization of polyps of the uterus with hysteroscopy is indeed a more informative diagnostic method and should be widely introduced into the clinical practice of treating women of reproductive age with endometrial hyperplastic processes in gynecological departments of hospitals.

\section{CONCLUSIONS}

Thus, the results of the subjective examination of patients in the gynecological department: complaints, anamnestic data on gynecological and extragenital pathology should be used to identify etiopathogenetic factors and the formation of risk groups for the occurrence of hyperplastic processes of endometrium.

Women with cervical erosion, uterine myoma and episodes of herpetic rash on the mucous membranes in past medical history have a higher likelihood of HPE.

The vast majority of patients $(63.87 \%)$ with polyps of the body of the uterus have a combined hyperproliferative pathology, which requires an individual approach to planning the scope of diagnostic examination and the choice of treatment method.

Visualization of endometrium with hysteroscopy is more informative than ultrasound for diagnosing hyperproliferative processes, including uterine polyps.

Hysteroscopic polypectomy has a high level of both clinical and economic benefits as well as diagnostic value in patients with HPE.

\section{REFERENCES}

1. MouhayarY., Yin 0., Mumford S.L.,Segars J.H. Hysteroscopic polypectomy prior to infertility treatment: $A$ cost analysis and systematic review. Eur. J. Obstet. Gynecol. Reprod. Biol 2017;213:107-115.

2. RCOG/BSGE Joint Guideline. Management of Endometrial Hyperplasia. Greentop Guideline 2016;67:1-31.

3. AAGL Practice Report. Practice Guidelines for the diagnosis and management of endometrial polyps. J Minim Invasive Gynecol. 2012 Jan-Feb;19(1):3-10. 
4. Pereira N., Petrini A.C., Lekovich J.P., Elias R.T., Spandorfer S.D. Surgical management of endometrial polyps in infertile women: a comprehensive review. Surg. Res. Pract. 2015;914390-7.

5. Yang J.H., Chen Ch.D., Chen Sh.U., Yang Y.Sh. et al. Factors influencing the recurrence potential of benign endometrial polyps after hysteroscopic polypectomy. PLoS One 2015;10(12):e0144857.

6. Mahmud A., Abbasher M., Nunes N., Hassan I. Imaging in gynaecology. Oral Presentation: Outcome of diagnostic hysteroscopy for suspected endometrial polyp on Ultrasound: the Birmingham Women's Experience. European Journal of Obstetrics \& Gynecology and Reproductive Biology 2016;206:128-193.

7. Wortman M. "See-and-treat" hysteroscopy in the management of endometrial polyps. Surg. Technol. Int. 2016;28:177-184.

8. Gkrozou F., Dimakopoulos G., Vrekoussis T., Lavasidis L. et al. Hysteroscopy in women with abnormal uterine bleeding: a metaanalysis on four major endometrial pathologies. Arch. Gynecol. Obstet. 2015;291(6):13471354.

9. Royal College of Obstetricians and Gynaecologists. Best practice in outpatient hysteroscopy. Green-top Guideline 2011;59:1-22.

10. Benyuk V.O., Vynyarsky Ya.M., Goncharenko V.M., Kurochka V.V. Diagnostic algorithm of intrauterine pathology with the use of hysteroscopy in women of reproductive age. Health of a woman 2009;6:54-56.

11. Senchuk A.Ya., Zub V.0., Chermak I.I., Karaim 0.S. Cryosurgery of prophylactic diseases of body mass. Collection of scientific works of the Association of Obstetricians-Gynecologists of Ukraine. Intermed 2009:539-544.
The work is carried out within the framework of the research work "Optimization of diagnosis and prevention of diseases of the reproductive system and development of pathogenically grounded methods for their correction" (state registration number 011 U001801).

\section{ORCID and contributionship:}

Alla V. Boychuk: 0000-0002-2191-0383 A, B, C, E,D

Tetiana V. Vereshchahina: 0000-0003-4629-0771 ${ }^{\text {A, B, C }}$

Irina M. Nikitina: 0000-0001-6595-2502 ${ }^{\mathrm{F}}$

\section{Conflict of interest:}

The Authors declare no conflict of interest.

\section{CORRESPONDING AUTHOR Iryna M. Nikitina \\ Sumy State University \\ 1A/112 Lermontova st., 40030 Sumy, Ukraine \\ tel: +380662947360 \\ e-mail:nikitina1med@gmail.com}

Received: 11.04 .2020

Accepted: 27.07 .2020

A - Work concept and design, B - Data collection and analysis, C - Responsibility for statistical analysis,

D - Writing the article, $\mathbf{E}$ - Critical review, $\mathbf{F}$ - Final approval of the article 